\title{
EVALUATION OF HOSPITAL INFORMATION SYSTEMS IN SELECTED HOSPITALS OF IRAN
}

\author{
Esmaeil Mehraeen ${ }^{1}$, Maryam Ahmadi $^{2} *$, Yousef Mehdipour ${ }^{3}$, Tayyebeh Noori ${ }^{4}$ \\ ${ }^{1}$ Health Information Technology MSc (Lecturer), Department of Health Information \\ Management, School of Health, Zabol University of Medical Sciences, Zabol, Iran. \\ ${ }^{2}$ Associate Professor in Health Information Management, School of Management and \\ Medical Information Sciences, Iran University of Medical Sciences,Tehran, Iran. \\ ${ }^{3}$ Assisstant Professor, Department of Health Information Management, Zahedan \\ University of Medical Sciences, Zahedan, Iran. \\ ${ }^{4}$ Health Information Technology MSc (Lecturer), Department of Health Information \\ Management, Zahedan University of Medical Sciences, Zahedan, Iran.
}

\begin{abstract}
Due to the information systems objectives, and to avoid duplication and to help improve care quality and reduce cost, it is necessary to conduct continuous evaluation to determine how to achieve these goals. This study was performed using evaluation indices of hospital Information systems (HIS) in selected hospitals of Iran. In this article organizational and server components of hospital information systems in selected hospitals are being assessed.

This research is a descriptive cross - sectional study. The study population consisted of the information system of Shohaday Tajrish, Khatamolanbiya, Imam Khomeini and Milad Hospital. Data collecting tools were checklist of hospital information system Evaluation Index, which completed with direct observation and interviews with users. Data analyzed by statistics software SPSS, and presented as statistical tables and graphs.

In the studied hospitals, although the most of the organizational components subgroups and hospital information system server components has been set up and used but pharmacy information system, decision support systems, communication services and telemedicine services hadn't been set up fully in the hospitals. Currently most subtypes of organizational components and hospital information system server components were fully in the designed software and considering all fields in 5 hospitals.
\end{abstract}

\section{KEYWORDS}

Assessment Index, Evaluation, Hospital, Hospital Information System

\section{INTRODUCTION}

Nowadays, due to the development of health information systems in health care centers, using equipment, software, and applications of these systems has also increased [1].Use of Hospital Information Systems is one concern in the health sector because of their increasing needs of the DOI : 10.5121/ijait.2014.4501 
International Journal of Advanced Information Technology (IJAIT) Vol. 4, No. 5, October 2014

growing complexity of health management processes and also due to the significant diversity and innovation in the supply system [2].

In general, the goal of health care information systems including hospital information systems is management of information, which health care staffs need for their efficiency and effectiveness of tasks and activities. Hospital information systems must be capable to support the high-quality health care services and meet the needs of its people [3].

Recently, due to the broad applications of ICT (Information and communication technology) in health systems, there is pressure on organizations' decision makers for the purchase and installation of these systems. However, it is rarely to discuss about the advantages and shortcomings of these technologies, because implementing information technology systems is often for utilizing the technology, regardless of the actual needs of the community [4]. Appropriateness of hospital information systems with healthcare practitioners` Work Programs cause that the expertise activities be easy for these practitioners [5].

On the other hand, if the design of hospital information systems be detailed, the effectiveness and productivity of health care occupant and patients` satisfaction will be increased and health care costs will be reduced [6]. In other words, non-compliance of hospital information system functions with existing processes can affect the cost and quality of health care. Therefore, due to the objectives of information systems, and to avoid duplication and to enhance quality and reduce costs, it is necessary to perform continuous assessment of hospitals information system software [7].

One of the important aims of the Hospital Information System software evaluation is promotion of these programs according to the Ministry of Health criteria, which continuously have been developed based on current needs and is notifying to the developer Company and universities [8]. Unfortunately, most of the software has been made due to the requirement of customer demand and not on the basis of a rational holistic and systemic approach. Also, different views affect the definition of hospital information system components that these different perspectives, derived from different needs of stakeholders or users of the system [9].

So, according to the adoption of hospital information systems in teaching hospitals in Iran and researchers` early familiar with these systems, the researchers went on to use "integrated hospital information system evaluation criteria", which was approved and published in 2011 by the Ministry of Health and Medical Education. We use these indices for evaluation of hospital information systems in selected hospitals in Iran, and by determining their weaknesses and noncompliance pointes help indicators and administrators for reform and more consistent with the evaluation criteria. Because by identifying needs, the way of solving problems and developing Hospital Information System will be paved, ultimately it is hoped that the quality of health care provided to patients will improve.

\section{METHODS}

Considering that the aim of this study was to evaluate hospital information systems, so among the hospitals in Tehran, hospitals were selected that had more perfect information systems are than others. Therefore, the study sample includes information system of Shohadaye Tajrish, Rasoole Akram, KhatamAlanbiya, Emam Khomeyni (5 hospitals and 100 information systems). 
The data collecting method was in this way that researcher referred to selected hospital and completed the checklist by direct observation and interviews with system users (130 people of 150 users were willing to interview). The data gathering tool in this study was hospital information system evaluation indexes checklist (list) of Health and Medical Education Department, which the checklist includes 9 enterprise (organizational) components and 11 hospital information system server components, along with the main subgroups and also their subsidiary subgroups. In this study, each of these subgroups has been considered as a feature that existence, lack and designing have been studied in the future of these features.

Like all methods of evaluation, according to the identified evaluation cases in a framework, they were given expert rating, in other words, they weighted from 1 to 10, that qualitative indicators were converted to quantitative and metric indices. To complete this framework, we referred to selected hospital and completed the checklist by direct observation and interviews with system users, that the data collected and after scoring, were analyzed and results were extracted. The data analyzed by statistics software SPSS, and presented as statistical tables and graphs.

\section{RESULTS AND DISCUSION}

\section{a.Evaluation results of the organizational components}

Evaluation results of the organizational components(including admission information systems, outpatient information systems, hospital wards information system, laboratory information systems, radiology information systems, operating room information system) showed that currently most of information systems were fully in the designed software and considering all fields in 5 hospitals. The only thing can be noted here is that, in pharmacy information system the average percentages of the features that wasn't in the software package and it was supposed to be considered in future versions of the software are more other two features (30out of 70 cases, $42.8 \%$ ) (See table 1).

Table1: The total number and percent of pharmacy information system subgroups evaluation

\begin{tabular}{|c|c|c|c|c|}
\hline Hospitals & $\begin{array}{l}\text { Feature Of } \\
\text { Software } \\
\text { Packages } \\
\end{array}$ & Number & Percent & Description Of Features \\
\hline \multirow{3}{*}{$\begin{array}{c}\text { Shohadaye } \\
\text { Tajrish }\end{array}$} & $\sqrt{ }$ & 4 & 28.6 & \multirow{5}{*}{$\begin{array}{l}\text { VCurrently this Features } \\
\text { fully in designed software } \\
\text { and by considering all the } \\
\text { fields. }\end{array}$} \\
\hline & * & - & 0 & \\
\hline & $x$ & 10 & 71.4 & \\
\hline \multirow{3}{*}{$\begin{array}{l}\text { Khatam } \\
\text { Alanbiya }\end{array}$} & $\sqrt{ }$ & 8 & 57.1 & \\
\hline & * & 4 & 28.6 & \\
\hline & $x$ & 2 & 14.3 & \multirow{7}{*}{$\begin{array}{l}\text { *This Feature currently } \\
\text { found in standard software } \\
\text { packages, but changes are } \\
\text { needed to achieve the } \\
\text { above. }\end{array}$} \\
\hline \multirow{3}{*}{$\begin{array}{c}\text { Emam } \\
\text { Khomeiny }\end{array}$} & $\sqrt{1}$ & 2 & 14.3 & \\
\hline & * & 4 & 28.6 & \\
\hline & $x$ & 8 & 57.1 & \\
\hline \multirow{3}{*}{$\begin{array}{l}\text { Hazrat } \\
\text { Rasool }\end{array}$} & $\sqrt{ }$ & 8 & 57.1 & \\
\hline & * & 4 & 28.6 & \\
\hline & $x$ & 2 & 14.3 & \\
\hline \multirow{3}{*}{ Milad } & $\sqrt{1}$ & 2 & 14.3 & \multirow{6}{*}{$\begin{array}{l}\text { This Feature is not } \\
\text { available on software } \\
\text { package and will be } \\
\text { considered in future } \\
\text { versions of the software }\end{array}$} \\
\hline & * & 4 & 28.6 & \\
\hline & $x$ & 8 & 57.1 & \\
\hline \multirow{3}{*}{$\begin{array}{l}\text { All the } \\
\text { hospitals }\end{array}$} & $\sqrt{ }$ & 24 & 34 & \\
\hline & $\star$ & 16 & 23.2 & \\
\hline & $x$ & 30 & 42.8 & \\
\hline
\end{tabular}


Also, the average percentage of the characteristics was significant in the information system of medical records ( 4 out of 15 cases, 26.7\%) and discharge (30 out of 100 cases, 36.2\%). In other words, all of the subgroups of pharmacy information system, medical records information System and discharge information system haven't been set up fully in the hospitals (See table 2).

Table 2: Percentage of organizational components

\begin{tabular}{|c|c|c|c|l|}
\hline \multirow{2}{*}{ Organizational Components } & \multicolumn{3}{|c|}{ Checklist Options } & \multirow{2}{*}{ Total } \\
\cline { 2 - 5 } & $\sqrt{ }$ & $\star$ & $\times$ & \\
\hline Admission Information System & 70 & 11.8 & 18.2 & 100 \\
\hline Outpatient Information System & 88 & 0 & 12 & 100 \\
\hline Hospital Wards Information System & 60 & 20 & 20 & 100 \\
\hline Pharmacy Information System & 34.3 & 22.9 & 42.8 & 100 \\
\hline Laboratory Information System & 68.7 & 12.2 & 19.1 & 100 \\
\hline Radiology Information System & 72.5 & 15 & 12.5 & 100 \\
\hline Operation Room Information System & 83.8 & 11.1 & 5.1 & 100 \\
\hline Medical Records Information System & 60 & 13.3 & 26.7 & 100 \\
\hline Discharge Information System & 42.5 & 21.3 & 36.2 & 100 \\
\hline
\end{tabular}

\section{b.Evaluation results of server components}

Evaluation results of the server components (including Electronic Medical Records, Nursing Information Systems, Bed Management Information Systems, Terminology Services, Security Services, Staffing and Scheduling Information Systems, Resource Management Information Systems, Nutrition Information System) showed that currently most of information systems were fully in the designed software and considering all fields in 5 hospitals. Only the decision support systems, communication services and telemedicine services, the average percentages of the features that weren't in the software packages of studied hospitals and it was supposed to be considered in future versions of the software are more other two features (see table 3). Also, in the terminology service, average percentage of a feature that has been present in standard software packages but the changes were needed to achieve the above, was impressive(12 out of 30 cases, $40 \%$ )(See table 4 ).

Table 3: Percentage of server components

\begin{tabular}{|c|c|c|c|c|}
\hline \multirow{2}{*}{ Server Components } & \multicolumn{3}{|c|}{ Checklist Options } & \multirow{2}{*}{ Total } \\
\cline { 2 - 4 } & $\sqrt[V]{ }$ & $\star$ & $\times$ & \\
\hline Electronic Health Record & 67.1 & 19.1 & 13.8 & 100 \\
\hline Nursing Information System & 65 & 12.5 & 22.5 & 100 \\
\hline Bed Management Information System & 44.4 & 26.7 & 28.9 & 100 \\
\hline Scheduling Information System & 80 & 12 & 8 & 100 \\
\hline Decision Support Information System & 12.5 & 25 & 62.5 & 100 \\
\hline Terminology Services & 60 & 40 & 0 & 100 \\
\hline Security Services & 72.3 & 15.4 & 12.3 & 100 \\
\hline Communication Services & 17.7 & 20 & 62.3 & 100 \\
\hline Telemedicine Services & 13.3 & 13.3 & 73.4 & 100 \\
\hline Resource Management Information System & 52 & 18 & 30 & 100 \\
\hline Nutrition Information System & 60 & 16 & 24 & 100 \\
\hline
\end{tabular}


International Journal of Advanced Information Technology (IJAIT) Vol. 4, No. 5, October 2014

Table4: The total number and percent of terminology service subgroups evaluation

\begin{tabular}{|c|c|c|c|c|}
\hline Hospital & $\begin{array}{c}\text { Feature Of } \\
\text { Software } \\
\text { Packages }\end{array}$ & Number & Percent & Description Of Features \\
\hline \multirow{3}{*}{$\begin{array}{c}\text { Shohadaye } \\
\text { Tajrish }\end{array}$} & $\sqrt{ }$ & 4 & 66.7 & \multirow{18}{*}{$\begin{array}{l}\text { बCurrently this Features } \\
\text { fully in designed software and } \\
\text { by considening all the fields. }\end{array}$} \\
\hline & $*$ & 2 & 33.3 & \\
\hline & $x$ & 0 & 0 & \\
\hline \multirow{3}{*}{$\begin{array}{l}\text { Khatam } \\
\text { Alanbiya }\end{array}$} & $\sqrt{1}$ & 3 & 50 & \\
\hline & $*$ & 3 & 50 & \\
\hline & $x$ & 0 & 0 & \\
\hline \multirow{3}{*}{$\begin{array}{c}\text { Emam } \\
\text { Khomeiny }\end{array}$} & $\sqrt{ }$ & 4 & 66.7 & \\
\hline & * & 2 & 33.3 & \\
\hline & $x$ & 0 & 0 & \\
\hline \multirow{3}{*}{$\begin{array}{l}\text { Hazrat } \\
\text { Rasool }\end{array}$} & $\sqrt{1}$ & 3 & 50 & \\
\hline & * & 3 & 50 & \\
\hline & $x$ & 0 & 0 & \\
\hline \multirow{3}{*}{ Milad } & $\sqrt{1}$ & 4 & 66.7 & \\
\hline & $*$ & 2 & 33.3 & \\
\hline & $x$ & 0 & 0 & \\
\hline \multirow{3}{*}{$\begin{array}{l}\text { All the } \\
\text { hospitals }\end{array}$} & $\sqrt{1}$ & 18 & 60 & \\
\hline & $*$ & 12 & 40 & \\
\hline & $x$ & 0 & 0 & \\
\hline
\end{tabular}

Hospital information systems support medical and clinical staff in their daily activities by means of electronic data processing exchanging. These systems cover subsystems in both inpatient and ambulatory care, so, they must be fully and complete. According to the results of the study it is possible to conclude that, currently most subgroups of organizational components and hospital information system server components were fully in the designed software and considering all fields in 5 hospitals. The only exception cases were pharmacy information system, decision support systems, communication services and telemedicine services, which some of their subgroups weren't in the software packages of studied hospitals and it was supposed to be considered in future versions of the software.

Similarly, the result of Salmela and Turunen study showed that the framework for evaluating medical alert systems benefits researchers. Its contribution is as a new means to help them study the impacts of such systems in clinical decision making. Practitioners can use the framework to review the potential benefits of alert systems in their own hospital. They can establish objectives for implementing such systems. And they can use the framework as an investigative tool in analyzing reasons for low organizational impact of an implemented alert system [10].

Also, the result of Ammenwerth et al study showed that a broadly accepted framework for evaluation of IT in healthcare seems desirable to address problems. Such a framework should help to formulate relevant questions, to find adequate methods and tools, and to apply them in a sensible way. Evaluation studies in health care IT take a lot of time, resources, and know-how. 
International Journal of Advanced Information Technology (IJAIT) Vol. 4, No. 5, October 2014

Research in the area of health care IT evaluation is just beginning. It is still mostly unclear how 'good' information systems should look like. Clearly defined methodological guidelines which take the difficulties of information system evaluation in health care into account may help to conduct better evaluation studies [11].

All of the healthcare organizations wants to provide accurate and timely health care for their customers and therefore, given the widespread use of hospital information systems and their dramatic impacts on healthcare provide and patient treatment, giving attention to all the features of hospital information systems and their inclusion in the software packages and focus on the organizational and server components of HIS (Hospital information systems) is recommended.

\section{CONCLUSION}

The main and subsidiary subtypes of organizational components and server components currently exist in all fields in the 5 hospitals software except pharmacy information systems, decision support systems, communication services and telemedicine service, that in these systems the average percentages of the feature: "This feature there is not currently in designed software and will be implemented in future versions of the software" more than other features. Due to the widespread adoption of hospital information systems in healthcare organizations, significant impact on patient treatment and according to the study results, the following suggestions are recommended:

1. Emphasize on characteristics that required for the implementation of HIS software

2. Evaluation of HIS in healthcare organizations

3. More focus on organizational and server components of HIS

\section{ACKNOWLEDGMENTS}

This study is part of the research project entitled "Evaluation of hospital information system in selected hospitals of Iran" that is supported by Tehran University of Medical Sciences.

\section{REFERENCES}

[1] Siamian H, Gonbadi K, Nasiri E, Shahrabi A (2005) Health information management role in hospital management. Elec J IrnScien Inform and Docum Cent 4(3):19-28.

[2] Moghaddasi H (2009) Information Focus and medical Hypermedia. Educ Press Assoc of Irn J Med Reco 3(7): 7-12.

[3] Hoseyni A (2002) Logical model design of information system for public-Teaching hospitals affiliated to medical universities in Tehran. Dissertation, Iran University of Medical Sciences, School of Management and Medical Information Sciences.

[4] Kaplan B, Maxwell J (2005) Qualitative Research Methods for Evaluating Computer Information SystemsEvaluating the Organizational Impact of Healthcare Information Systems.Volume 1. 2nd edition. USA: Springer:30-55.

[5] Borzekowski R (2009) Measuring the Cost Impact of Hospital Information Systems: 1987-1994. Journal of Health Economics 28(5):938-949.

[6] Mehraeen E, AhmadiM, Shajarat M, Khoshgam M (2012)Assessment of hospital information system in selected hospitals in tehran. Journal of PayavardSalamat6(6):458-466. 
International Journal of Advanced Information Technology (IJAIT) Vol. 4, No. 5, October 2014

[7] Hoffman EK, Finnegan R, yakul MA (2008) Medical record management.Volume 2. 3nd edition. Berwyn: physician's record company:543.

[8] Design and implementation of health information systems(2011) http://ict1.tbzmed.ac.ir/healthbank/online\%20education/pdf\%20book.pdf. Accessed 2 Apr 2010.

[9] Reinhold H (2007) Health information systems - past, present, future. Inte J med inform75(3-4): 268281.

[10] Salmela H, Turunen P (2011) Evaluation of information systems in health care: a framework and its application.

http://citeseerx.ist.psu.edu/viewdoc/download?doi=10.1.1.199.8598\&rep=rep1\&type=pdf. Accessed 10 June2012.

[11] Ammenwerth E, Gräber S, Herrmann G, Bürkle T, König J (2003) Evaluation of health information systems-problems and challenges. Int J Med Inform71(2-3):125-135. 